\title{
THE DRUNKEN DRIVER: A PSYCHOSOCIAL STUDY
}

\author{
MELVIN L. SFL7FR and EUGENIA BARTON
}

Department of Psychiatry, University of Michigan Medical School, 900 Wall Street, Ann Arbor, Michigan 48105 (U.S.A.)

(Received January 28, 1977)

\section{Summary}

A self-administered questionnaire was used to compare selected psychosocial variables of 306 convicted male drunk drivers with those of 294 alcoholics and 253 controls.

The drunk driver group fell between the other groups on many parameters but resembled the alcoholic group on many others. While over $68 \%$ of the drunk drivers appeared to be alcoholics, in general they showed significantly less psychosocial incapacity than the alcoholic comparison group. The differences between the alcoholic and presumed non-alcoholic drunk drivers were not sufficient to clearly dichotomize the drunk driver group.

\section{Introduction}

Although it is clear that most persons arrested for drunken driving have serious alcoholism problems [1 - 5], much uncertainty remains about the psychosocial characteristics of drunk driving populations. Who are they and why do they permit themselves to be compromised by an arrest for a universally condemned and potentially dangerous activity? Two previous psychosocial studies indicated that convicted drunk drivers included alcoholics who were not as psychosocially impaired as were alcoholics in treatment programs and others who, although not alcoholic, were nevertheless significantly different from a control group, the differences pointing toward characteristics seen in alcoholics $[6,7]$. The current study was undertaken to clarify and confirm these earlier impressions and to depict more clearly the drinking, personality and social characteristics of a drunk driving population.

Since those arrested for drunk driving are preponderantly males, all subjects in this study were males. 


\section{Method}

\section{Procedure}

A questionnaire was used consisting of items developed for the present and previous studies $[6,7]$, as well as standardized measures used elsewhere. Adequate reliability was established wherever a modified shorter scale was substituted for the original $(\alpha>0.59)$. Some measures consisted of single items, others were indices constructed from sets of these items based on a cluster analysis of similar data gathered earlier [7]. Scores of the indices were derived by taking a mean from scores on the individual items within each cluster.

Differences between the three groups are reported only when significant at the 0.01 level.

\section{Subjects}

The sample consisted of three groups: drunk drivers, alcoholics, and licensed drivers. The drunk driver group (Group D) consisted of 306 drivers convicted of alcohol-impaired (blood level $0.07-0.09 \%$ ) or intoxicated (blood level $0.10 \%$ and higher) driving in two Michigan counties; these drivers were thereafter required to participate in counseling programs and to fill out the questionnaire.

The 294 alcoholic respondents (Group A) were drawn equally from inpatient and out-patient alcoholism treatment programs located in several south-eastern Michigan cities. All patients in those programs during a fourmonth period were required to fill out the questionnaire. There were no significant differences for any of the variables between the in-patient and out-patient groups.

The control group (Group L) consisted of 253 drivers in three Michigan counties who were offered $\$ 3.00$ to fill out the 35 minute questionnaire immediately after they had routinely renewed their driver's licenses. An appeal was made outlining the potential importance of the study. Some $50 \%$ of those approached filled out the questionnaire, while most of the others pleaded lack of time. This group does not qualify as a random sample because many subjects could not or would not make out the lengthy questionnaire, but no random method to recruit a large voluntary control population was available.

The Crowne--Marlowe Social Desirability Scale [8] was used to correct the data for subject tendency to assert good and deny bad things about themselves. Seven statements with a yes-no response format comprised an Assert Good scale and seven items a Deny Bad scale. The Assert Good scale included such items as "I have never deliberately said something that hurt someone's feelings" and "I never hesitate to go out of my way to help someone in trouble". The three groups were statistically similar on the Assert Good scale, although the drunk drivers were most prone to say good things about themselves. However, the seven-item Deny Bad scale ("I sometimes feel resentful when I don't get my way", "I am sometimes irritated by people 
who ask favors of me", etc.) revealed significant differences. Drunk drivers $(M=4.00$, seven point scale) and the licensed drivers $(M=4.04)$ were alike, while the alcoholics $(M=2.32)$ were significantly less likely to deny bad things about themselves $(P>0.0001)$

Given the above defensive differences, it was necessary to correct the response means to other questionnaire variables. Therefore, an analysis of covariance was performed on the data which allowed a between-group comparison for adjusting means upward or downward to compensate for the subjects' varying tendencies to minimize bad responses about themselves. Data reported in this paper, with the exception of the demographic data and the results of the Short Michigan Alcoholism Screening Test $[9,10]$, were adjusted to account for these differences.

\section{Results}

The results of this study are presented in three sections. The first two compare the three groups for variables related to differences in drinking characteristics and psychosocial characteristics. The third explores whether the drunk driver sample is made up of two discrete groups: social drinkers and alcoholics. Demographic data appear in Table 1.

TABLE 1

Demographic data

\begin{tabular}{lccc}
\hline & \multicolumn{3}{l}{ Means } \\
& $\begin{array}{l}\text { Group A } \\
(N=294)\end{array}$ & $\begin{array}{c}\text { Group D } \\
(N=306)\end{array}$ & $\begin{array}{l}\text { Group L } \\
(N=253)\end{array}$ \\
\hline Age & 33.2 & 37.3 & 35.1 \\
Education (years) & 11.5 & 11.4 & 13.6 \\
Income (\$/year) & 10500 & 10400 & 12500 \\
Race (\%) & & & \\
$\quad$ White & 81 & 86 & 83 \\
$\quad$ Black & 13 & 9 & 14 \\
$\quad$ Other & 6 & 5 & 3 \\
\hline
\end{tabular}

\section{Drinking characteristics}

A primary goal of the survey was to differentiate the drinking characteristics of convicted drunk drivers, alcoholics, and the licensed drivers. In order to determine how many of the drunk drivers were alcoholics, subjects were given the Short Michigan Alcoholism Screening Test (SMAST) [10] . The 13-item SMAST was designed to detect alcoholism with a score of zero to one point in the normal range, two points indicating possible alcoholism, and three or more points indicating alcoholism. In the drunk driver group 
$68 \%$ fell in the alcoholic range and $15 \%$ in the borderline or possible range. Given the earlier demonstrated tendency of drunk drivers to minimize their bad traits, the uncorrected SMAST scores for the drunk driver group probably yielded a slightly low estimate of the actual number of alcoholics.

The survey also compared alcohol consumption among the three groups. Respondents rated their drinking category by selecting the best self-description from a list of eight alternatives. The eight options included "Nondrinker", "Very light drinker", "Light drinker", ranging up to "Alcoholic". Drunk drivers ( $M=4.17$, eight point scale) scored between the alcoholics $(M=6.54)$, who described themselves as the heaviest drinkers, and the licensed drivers $(M=2.46)$, the lightest drinkers $(P<0.0001)$.

The three sample groups also exhibited significant drinking variations in terms of quantity and frequency. Excluding some $10 \%$ of the licensed drivers who said they had not consumed alcohol within the last three years, respondents were asked how frequently they drank beer, liquor, or wine, ranging from "Never" to "Almost every day". Summing the mean frequencies of drinking of all three beverage categories, drunk drivers $(M=11.27$, twentyone point scale) and licensed drivers $(M=10.62)$ both drank less frequently than the alcoholic drivers $(M=13.16, P<0.0001)$.

Subjects were asked how many 8-ounce glasses of beer, 4-ounce glasses of wine, and 1-ounce shots of hard liquor they drank per occasion. As might be expected, the three groups showed significant differences. Drunk drivers drank less hard liquor per occasion ( $M=4.55$ ounces) than the alcoholics ( $M=8.83$ ounces), but more than the licensed drivers $(M=2.53$ ounces, $P<0.0001)$. The same pattern emerged in the consumption of beer, with Group D drinking less beer $(M=5.00$ glasses $)$ than the alcoholics $(M=8.13$ glasses), but more than the licensed driver group ( $M=2.73$ glasses, $P<$ $0.0001)$. The differences were less pronounced but still significant for wine. Group D drank less wine per occasion ( $M=3.43$ glasses) than the alcoholics $(M=4.80$ glasses $)$, but more than the licensed drivers $(M=2.16$ glasses, $P<0.0001)$. Thus, while the drunk drivers and the licensed drivers were statistically similar in frequency of drinking, Group D consumed considerably more alcohol in all forms than the licensed group - and significantly less than the alcoholics.

Another focus of the study concerned the effects of excessive drinking on driving. The respondents' propensity to drive after drinking and their record of arrests for drunken driving were ascertained. Subjects were asked how many times during the prior twelve months they had driven after having had four or more drinks (equivalent to four or more ounces of whiskey). Group D had the highest proportion (97.4\%) of those who had driven under these circumstances at least once, in comparison with the alcoholic group $(92.3 \%)$ or the licensed drivers $(61.5 \% P<0.0001)$. Averaging the number of times subjects drove after drinking four or more drinks during the previous year, drunk drivers $(M=6.03)$ and alcoholics $(M=6.29)$ drove in such a condition significantly more times than the licensed drivers $(M=3.89$, $P<0.0001$ ). 
The mean number of arrests for drunken driving during the prior three years was significantly different among the groups. The drunk drivers had more arrests $(M=1.38)$ than the alcoholics $(M=1.12, P<0.01)$ and the control drivers $(M=0.07, P<0.001)$.

\section{Psychosocial variables}

\section{Reasons for drinking}

Respondents were asked their reasons for drinking with five yes-no questions developed by Cahalan $e \ell$ cl. [11]. A hierarchal cluster analysis [12] separated the reasons for drinking into two subcomponents: tension relief and social relaxation. The three items which comprised the tension relief cluster were: "I drink when I am low/depressed", "I drink because it helps me to forget my worries" and "I drink because I need it when tense and nervous". The two social relaxation items were: "I drink because it helps me to overcome being shy with people" and "I drink because it helps me to relax".

One of the biggest differences among the three groups emerged in the "reasons for drinking" variable. As Table 2 shows, the drunk drivers fell in the middle range between alcoholics and licensed drivers who were at opposite extremes. The drunk drivers drank significantly less for tension relief $(M=1.09)$ than the alcoholics $(M=2.33)$, but more than the licensed drivers $(M=0.36)$. Similarly, drunk drivers said they drank less for social relaxation $(M=1.21)$ than the alcoholics $(M=1.49)$, but more than the licensed drivers $(M=0.84)$. Only the alcoholic group indicated that they drank more for tension relief than for social relaxation.

TABLE 2

Reasons for and effects of drinking

\begin{tabular}{|c|c|c|c|c|c|c|}
\hline & \multicolumn{3}{|l|}{ Means } & \multicolumn{3}{|l|}{$T$-scores } \\
\hline & Group A & Group D & Group L & $A-D$ & $A \cdot L$ & D-L \\
\hline \multicolumn{7}{|l|}{ Reasons for drinking } \\
\hline $\begin{array}{l}\text { Tension relief } \\
3 \text { items } \\
\text { Range }=0-3\end{array}$ & 2.33 & 1.09 & 0.36 & $16.43^{*}$ & $24.78 *$ & $9.82^{*}$ \\
\hline $\begin{array}{l}\text { Social relaxation } \\
2 \text { items } \\
\text { Range }=0-2\end{array}$ & 1.49 & 1.21 & 0.84 & $5.17 *$ & $11.67 *$ & $7.27 *$ \\
\hline $\begin{array}{l}\text { Troublesome } \\
3 \text { items } \\
\text { Range }=0 \cdot 3\end{array}$ & 1.62 & 0.49 & 0.15 & $16.23^{*}$ & $20.62 *$ & $5.54^{*}$ \\
\hline $\begin{array}{l}\text { Comfortable } \\
5 \text { items } \\
\text { Range }=0-5\end{array}$ & 4.06 & 3.31 & 2.38 & $6.91 *$ & $14.68 *$ & $8.71^{*}$ \\
\hline
\end{tabular}

$* P<0.0001$ 


\section{Effects of drinking}

In order to further assess the differences in motivation for drinking, respondents were asked whether they had experienced certain effects from drinking. A hierarchal cluster analysis separated the responses to the eight yes-no questions into two categories (Table 2). One cluster was labeled "troublesome effects", and included "Makes me depressed or gloomy", "Makes me lose control of myself" and "Makes me get into trouble with people". The other cluster, labeled "comfortable effects", included "Makes me relaxed", "Makes me comfortable with people", "Makes me happy", "Makes me feel more free to do the things I want to do" and "Makes me feel less concerned about my problems".

The "effects of drinking" items revealed a response pattern similar to the "reasons for drinking" responses in that the drunk drivers experienced more intense effects from drinking than the licensed drivers, but less than the alcoholic drivers. Table 2 shows that Group D had more troublesome effects $(M=0.49)$ than the licensed drivers $(M=0.15)$, but less than the alcoholic drivers $(M=1.62)$. In addition, Group D experienced more comfortable effects $(M=3.31)$ than the licensed drivers $(M=2.38)$, but less than the alcoholics $(M=4.06)$.

\section{Stress}

As one parameter of stress among the three groups, subjects were asked how frequently they had problems with wives, children, parents, or in-laws which made them angry, worried, or irritated. The six frequency options ranged from "Several times a week" to "Once a year or less". Responses were combined as "family problems" and appear in Table 3.

Table 3

Family and job problems

\begin{tabular}{|c|c|c|c|c|c|c|}
\hline & \multicolumn{3}{|l|}{ Means } & \multicolumn{3}{|l|}{$T$-scores } \\
\hline & Group A & Group D & Group L & $A \cdot D$ & $A-L$ & D-L \\
\hline $\begin{array}{l}\text { Family problem frequency } \\
\text { Items }=3 \\
\text { Range }=0-18\end{array}$ & 9.11 & 8.43 & 7.65 & 1.87 & $4.15^{*}$ & 2.41 \\
\hline $\begin{array}{l}\text { Family problem distress } \\
\text { Items }=3 \\
\text { Range }=0 \cdot 15\end{array}$ & 7.99 & 8.13 & 6.52 & 0.29 & $3.37 * *$ & $3.23^{* * *}$ \\
\hline $\begin{array}{l}\text { Job problem frequency } \\
\text { Items }=2 \\
\text { Range }=0-12\end{array}$ & 7.04 & 6.08 & 6.23 & $3.75 * *$ & $3,01 * * *$ & 0.60 \\
\hline $\begin{array}{l}\text { Job problem distress } \\
\text { Items }=2 \\
\text { Range }=0-10\end{array}$ & 5.51 & 5.29 & 4.87 & 1.02 & $2.95 * * *$ & 1.92 \\
\hline
\end{tabular}

$* P<0.0001 \quad * * P<0.001 \quad * * * P<0.01$ 
Subjects also indicated the degree of distress caused by these family problems on a five point scale ranging from "Extremely disturbing" to "Not disturbing at all" (family problems distress, Table 3 ).

As shown in Table 3, family problems ranged in the expected direction, with alcoholics and drunk drivers more troubled than the controls. The alcoholics clearly had more family problems $(M=9.11)$ than the licensed drivers $(M=7.65)$. The difference in means between Group D $(M=8.43)$ and the licensed drivers approached a 0.01 significance $(P=0.0162)$. However, the alcoholics $(M=7.99)$ and drunk drivers $(M=8.13)$ were statistically similar for "family problems distress", with both more troubled than the licensed driver group $(M=7.65)$.

Similar questions and response scales were used for respondents' job situations (Table 3). The "job problem frequency" cluster included "How often do you find yourself tense while at your job, having no time to relax for a while?" and "How often do you have problems with your bosses, subordinates, or co-workers that make you seriously irritated, angry, or aggravated?". The "job problem distress" category included two items: how serious and disturbing the respondent considered his job problems to be, and how much distress was experienced from problems with bosses, subordinates, or co-workers. Surprisingly, the job stress data revealed no differences between Groups D and L, with Group A acknowledging significantly more job problems.

\section{Coping with lension and depression}

Another objective of the survey was to determine if the three groups differed in their approaches to coping with depression and tension. Subjects were asked how frequently they dealt with depression and tension by: smoking a great deal; having a drink; taking pills or other medicine; thinking it over; talking problems over with someone; doing something physically active; going to see a movie or play, or to hear some music. The five frequency options were "Never", "Seldom", "Sometimes", "Often", and "Always".

Two clusters emerged from a hierarchal cluster analysis of the data [12]. One cluster, "coping, oral substance use", included taking pills or other medicine, smoking, and having a drink. The second cluster, "coping, non-oral" included the remaining practices. As seen in Table 4, the drunk drivers relied significantly less on oral substances to cope with tension and depression than the alcoholics, but significantly more than the license group.

When "Having a drink" was excluded from the oral cluster, a similar response pattern emerged (Table 4).

In order to develop a more complete picture of the reliance on oral coping methods, the survey included questions on specific drug-taking patterns (Table 5). Subjects were asked how often they took sedatives, "downers", tranquilizers, stimulants, marihuana, and LSD. The five point scale ranged from "Never" to "Several times a week". The drunk drivers used significantly more marihuana, stimulants, and LSD than the licensed drivers and more marihuana than the alcoholics. The drunk drivers were 
TABLE 4 Methods of coping with depression and tension

\begin{tabular}{|c|c|c|c|c|c|c|}
\hline \multirow[t]{2}{*}{ Method of coping } & \multicolumn{3}{|l|}{ Means } & \multicolumn{3}{|c|}{$T$-scores } \\
\hline & Group A & Group D & Group L & $A \cdot D$ & A-L & $D \cdot L$ \\
\hline $\begin{array}{l}\text { Oral substance use } \\
\text { Items }=3 \\
\text { Range }=0-12\end{array}$ & 5.60 & 4.50 & 2.63 & $5.68^{*}$ & $14.62^{*}$ & $9.92 *$ \\
\hline $\begin{array}{l}\text { Non-oral methods } \\
\text { Items }=5 \\
\text { Range }=0-8 \\
\text { Oral substance use, } \\
\text { minus item "having }\end{array}$ & 8.21 & 8.36 & 9.09 & 0.66 & $3.57 * *$ & $3.17 * * *$ \\
\hline $\begin{array}{l}\text { a drink" } \\
\text { Items }=2 \\
\text { Range }=0-8\end{array}$ & 3.44 & 2.58 & 1.64 & $5.92 *$ & $11.82 *$ & $6.66^{*}$ \\
\hline
\end{tabular}

TABLE 5 Frequency of drug use

\begin{tabular}{|c|c|c|c|c|c|c|}
\hline \multirow[t]{2}{*}{ Drug $^{\mathrm{a}}$} & \multicolumn{3}{|l|}{ Means } & \multicolumn{2}{|l|}{$T$-scores } & \multirow[b]{2}{*}{ D-L } \\
\hline & Group A & Group D & Group L & A-D & $A-L$ & \\
\hline Downers & 1.64 & 1.36 & 1.21 & $3.08 * * *$ & $4.43^{*}$ & 1.61 \\
\hline Tranquilizers & 2.20 & 1.70 & 1.48 & $3.74 * * *$ & $5.17 *$ & 1.73 \\
\hline Stimulants & 1.17 & 1.24 & 1.08 & 1.06 & 1.48 & $2.68 * * *$ \\
\hline Marihuana & 1.43 & 2.01 & 1.53 & $4.66^{*}$ & 0.75 & $3.99 *$ \\
\hline LSD & 1.05 & 1.14 & 1.04 & 2.41 & 0.19 & $2.68 * * *$ \\
\hline
\end{tabular}

similar to the licensed drivers in their use of sedatives and tranquilizers, with both groups using substantially less than the alcoholics.

\section{Neuroticism}

The survey included six items from the Eysenck Neuroticism Scale [13] . Eysenck defined neuroticism as "the general emotional instability of a person, his emotional over-responsiveness, and his liability to neurotic breakdown under stress". The items selected from the Neuroticism Scale included "Are you troubled with feelings of inferiority?", "Are your feelings rather easily hurt?", "Would you call yourself tense or highly strung?", "Would you call yourself a nervous person?", "Are you often troubled by feelings of guilt?" and "Does your mood often go up and down?". Responses to the individual questions appear in Table 6.

On the whole, the three groups displayed different degrees of "neuroticism", with drunk drivers $(M=1.87)$ indicating less than the alcoholics $(M=3.42)$, but more than the licensed drivers $(M=1.40)$ (Table 7$)$. 
TABLE 6

Individual neuroticism items

\begin{tabular}{|c|c|c|c|c|c|c|}
\hline & \multicolumn{3}{|l|}{ Means } & \multicolumn{3}{|c|}{$T$-scores } \\
\hline & Group A & Group D & Group L & $A-D$ & $A \cdot L$ & D-L \\
\hline Inferiority feelings & 1.51 & 1.14 & 1.12 & $7.86^{*}$ & $8.29 *$ & 0.87 \\
\hline Hurt feelings & 1.57 & 1.38 & 1.34 & $4.77^{*}$ & $5.52 *$ & 1.05 \\
\hline High strung & 1.56 & 1.30 & 1.18 & $6.90 *$ & $9.56^{*}$ & $3.21 *$ \\
\hline Nervous & 1.61 & 1.36 & 1.20 & $6.33 *$ & $9.83 *$ & $4.09 *$ \\
\hline Guilty & 1.56 & 1.18 & 1.13 & $11.48^{*}$ & $12.42^{*}$ & 1.59 \\
\hline Mood swings & 1.70 & 1.47 & 1.38 & $6.17^{*}$ & $8.19 *$ & 2.49 \\
\hline
\end{tabular}

$* P<0.0001 \quad * * * P<0.01$

TABLE 7

Psychological variables

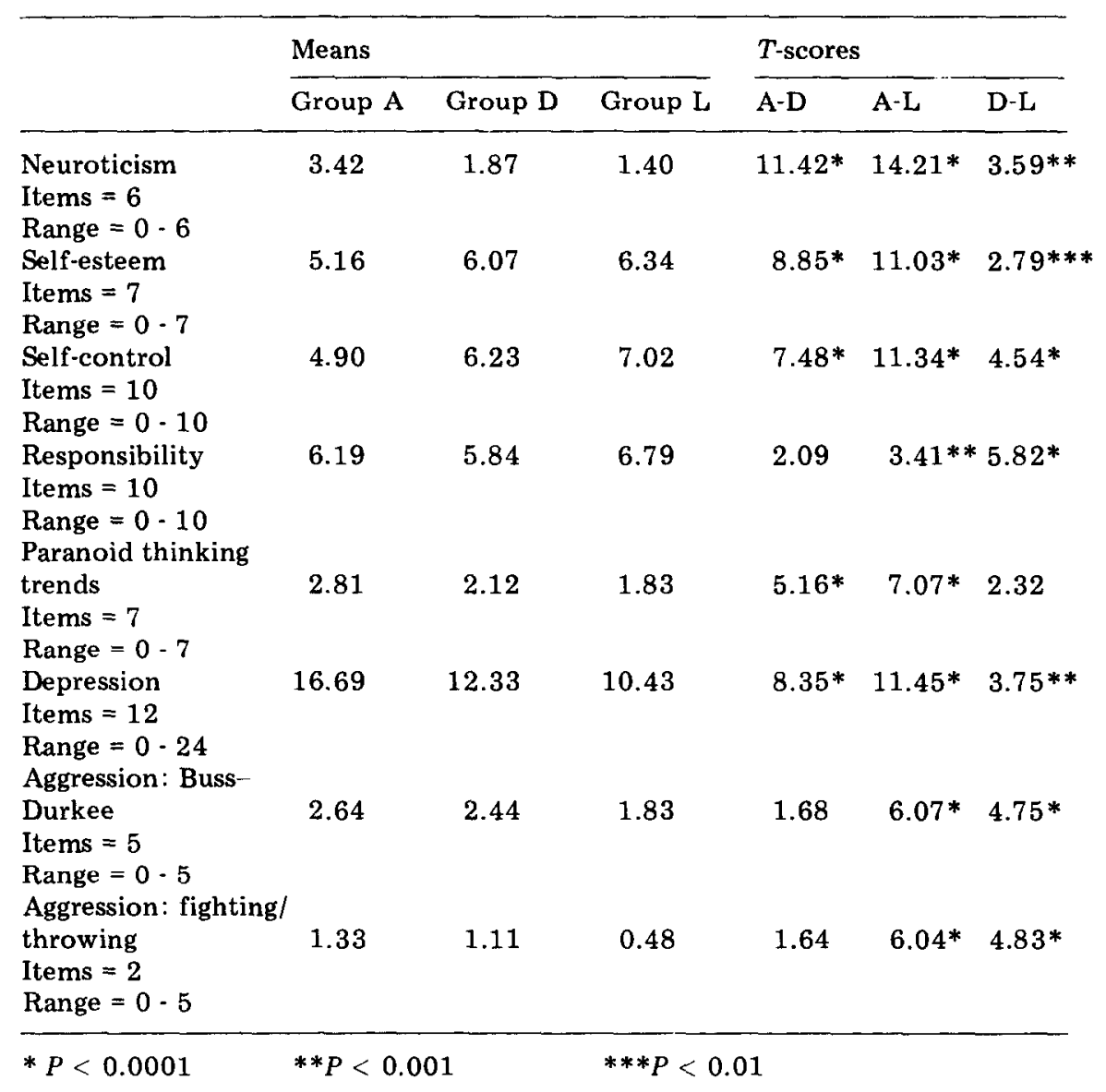




\section{Self-esteem}

The survey included a self-esteem scale [14] in which respondents were asked to agree or disagree with seven statements such as "I am able to do things as well as most other people", "On the whole, I am satisfied with myself", "I feel that I have a number of good qualities". Table 7 indicates that the drunk drivers had less self-esteem than the licensed drivers, but more than the alcoholic drivers.

\section{Self-control}

The degree of control over one's impulses was another variable thought to be a likely discriminator among the groups. Obviously, alcoholics cannot control their drinking and drunk drivers are unable to control circumstances that lead them to drive in a potentially dangerous manner.

Ten self-control items from the California Psychological Inventory [15] were used. Subjects were asked to agree or disagree with statements such as: "I get excited very easily", "I often act on the spur of the moment without stopping to think", "I often lose my temper", "I must admit I often try to get my own way regardless of what others may want".

The data revealed that the drunk drivers had less self-control than the licensed drivers, but more than the alcoholics (Table 7).

\section{Responsibility}

A potentially important psychological variable in assessing drunk drivers is the degree of responsibility they feel toward others. Responsibility in this survey refers to an individual's appreciation of the need to participate in and live by the rules of the community. The responsibility scale consisted of ten questions from the California Psychological Inventory [15]. Subjects were asked whether they agreed with such items as "A person who doesn't vote is not a good citizen", "If I get too much change in a store, I always give it back", and "It's no use worrying my head about public affairs; I can't do anything about them any way". The drunk drivers $(M=5.84)$ and alcoholics $(M=6.19)$ were similar to each other with lower scores on expressed levels of responsibility than the license group $(M=6.79)$, who were significantly more responsible (Table 7).

\section{Paranoid thinking}

To determine the presence of paranoid thinking trends, five items from the Buss-Durkee Inventory [16] were used for an index of paranoid thinking. Subjects agreed or disagreed with statements such as: "I know that people tend to talk about me behind my back" and "I usually wonder what hidden reason another person may have for doing something nice for me". In addition, two other items were included in the scale: "I often feel that someone holds a grudge against me" and "There are a number of people who seem to be jealous of me". Drunk drivers $(M=2.12)$ and licensed drivers $(M=1.83)$ were similar on this variable, with both much less paranoid than the alcoholics $(M=2.81)$ (Table 7). 


\section{Depression}

A modified version of the Short Zung Self Rating Depression Scale was used, consisting of twelve questions which are essentially affect-related ("blue", "crying") or elicit symptoms associated with depression ("I get tired for no reason", "... trouble sleeping", etc.) [17]. Respondents checked how frequently they experienced these feelings on a five point scale ranging from "Never" to "Always". The drunk drivers $(M=12.33)$ were more depressed than the licensed driver group $(M=10.32)$, but less so than the alcoholics $(M=16.69)$ (Table 7$)$.

\section{Aggression}

It was hypothesized that Groups $\mathrm{A}$ and $\mathrm{D}$ would be more aggressive than the licensed drivers because of their impulse control difficulties. The study included five items from the Buss-Durkee Aggression Inventory [16] Subjects were asked to agree or disagree with five statements reflecting aggressive and irritable feelings, such as, "If someone hits me first, I let him have it" and "If somebody annoys me, I am apt to tell him what I think of him". Table 7 indicates that the drunk drivers and the alcoholics were similar to each other on this variable with both showing more aggressive qualities than the licensed driver group.

In addition to the Buss - Durkee items, two other items were included: "How often during the past year have you been involved in a fist fight" and "How often during the past year did you become so angry that you threw or broke things?"'. Subjects were asked to indicate how often this had occurred on a five point scale ranging from "Never" to "Four times or more". The drunk drivers $(M=1.11)$ and the alcoholics $(M=1.33)$ were much more violent than the licensed drivers $(M=0.48)$ (Table 7$)$.

\section{Comparative analysis}

The three sample populations were examined in terms of group means. On many measures, the drunk drivers had less extreme scores than the alcoholics, yet indicated more serious problems than those of the control group. However, as in an earlier study [7], on some measures the drunk drivers were statistically similar to the alcoholic group. On a few others, they were similar to the licensed driver group.

The following are some of the variables for which Group D had less extreme scores than the alcoholics, but scored higher than the licensed driver group: the SM $\Lambda$ ST scale, self-classification as drinker, frequency of drinking and amount of alcohol consumed, drinking for tension relief and social relaxation, troublesome and comfortable effects from drinking, use of oral substances (drugs) for coping with tension and depression, self-control, neuroticism, depression, and self-esteem.

While Group D's scores on these variables point to their collectively not having problems as severe as those of the alcoholics, they were statistically indistinguishable from the alcoholics on other variables, including frequency of family problems, responsibility and aggressiveness. The drunk driver profile 
is further complicated by the fact they were statistically similar to the licensed driver group on other measures: job problems and paranoid thinking trends.

The drunk driver group was separated into three categories according to their SMAST scores. Those who scored zero to one point were in the SMAST non-alcoholic category $(N=51)$, those who scored two points were rated as possible alcoholics $(N=41)$, while those who scored three or more points were in the alcoholic range $(N=209)$. Our purpose was to see whether Group $\mathrm{D}$ consisted of two basic groupings: social drinkers and alcoholics. This would be the case if the latter's (high SMAST) variable scores were similar to Group A's scores and the low SMAST drunk drivers' scores were like those of Group L. (The D drivers who were possible alcoholics based on a two point score were excluded.) Thus, "low SMAST" (presumably non-alcoholic) drunk drivers, "high SMAST" drunk drivers, licensed control drivers and the alcoholic group were compared.

The comparison between low and high SMAST score drunk drivers showed significant differences $(P<0.05)$ on most of the variables with the exception of non-oral methods of coping with tension and anxiety, experiencing uncomfortable effects from drinking, aggression, self-esteem, responsibility and self-control.

In effect, the differences were not strong enough to polarize the drunk driver sample into two discrete groups, i.e. social drinkers and alcoholics. A dichotomization of the drunk driver group into alcoholics and social drinkers would require that the high SMAST drunk drivers consistently score the same as the alcoholics, and the low SMAST drunk drivers score in the same range as the licensed drivers. It also would require that low and high SMAST drivers score differently from each other.

Low SMAST drunk drivers were statistically similar to the licensed drivers and at the same time different from the high (presumably alcoholic) SMAST drunk drivers only on the following variables: drinking for social relaxalion, depression, neuroticism, paranoid thinking, and the number of non-drinking related arrests.

On none of the variables were the high SMAST drunk drivers both statistically different from the low SMAST drivers and similar to Group A.

In order to find the variables which best predicted whether a subject was a drunk driver, an alcoholic or a licensed driver, a discriminant function analysis using the eleven most significant variables was employed. The most powerful variables for predicting a subject's category appear in Table 8.

\section{Discussion}

One salient, though not unexpected, finding in this study was that over $68 \%$ of the men arrested for drunk driving were alcoholics. Similar data have been reported for decades [ $1-7]$. It is worth re-emphasis here because of continued official resistance to the knowledge that most drunk drivers are alcoholics [18]. 


\section{TABLE 8}

Discriminant function analysis predicting to category

\begin{tabular}{lcl}
\hline & $F$ statistic & Significance \\
\hline Drinking related arrests & 69.852 & 0.0000 \\
Troublesome drinking effects & 47.338 & 0.0000 \\
Drinking for tension relief & 46.453 & 0.0000 \\
Coping with tension: pills and smoking & 9.9526 & 0.0001 \\
Somatic stress symptoms & 6.3122 & 0.0019 \\
Neuroticism & 6.6850 & 0.0013 \\
Responsibility & 6.0457 & 0.0025 \\
Paranoid thinking & 3.8466 & 0.0217 \\
Comfortable drinking effects & 3.6942 & 0.0253 \\
Self-esteem & 3.6796 & 0.0256 \\
Social relaxation & 3.4068 & 0.0336 \\
\hline
\end{tabular}

What additional factors were present in the drunk driver population that could contribute to their drunken driving conduct? When compared to the control group, the drunk drivers were more aggressive, more depressed, had less self-esteem, less responsibility and less self-control. Factors such as low responsibility and impaired self-control imply a quality of impulsivity that may explain the difficulty in finding solutions to the drunken driving problem.

Our data indicate that most drunk drivers - whether or not they are alcoholics - usually have distinctive psychosocial and drinking problems. Most would undoubtedly benefit from rehabilitative programs. One problem in establishing rehabilitation programs for them is that drunken driving is not a definable illness - it is an event that must first occur before any curative effort can be mobilized.

Another almost paralyzing deterrent is the sheer number of drunk drivers and how very few can be apprehended [19]. Indeed, there is reason to believe that apprehension and conviction of drunk drivers, as presently implemented, is a waste of time, both in terms of those apprehended [20, 21 ] and because of the myriads of undeterred drunk drivers not apprehended at all.

Although the overall problem probably cannot presently be modified given our present enforcement system, the case finding importance of drunken driving arrests should not be overlooked. Many alcoholics are now successfully treated following a drunken driving arrest. Had these drivers not been arrested, their treatment would not have taken place for many more selfdestructive years.

What can be done to reduce the high incidence of drunken driving? Methods to deter drivers before they become drunk drivers are essential. Attempts to educate or appeal directly to the driving public have not been particularly successful. Neither have those strategies which relied on stringent penalties, particularly the long-overrated Swedish approach [21]. Is there 
anything in the data provided in this paper that could lead to a meaningful approach to the not-yet apprehended drunk driver? Unfortunately, our data discourage any idea of a direct approach to the drivers themselves. Most are alcoholics, and we are not aware of any public relations method for successfully coping with that syndrome. Furthermore, many of both the alcoholic and non-alcoholic drunk drivers had forms of psychosocial impairment that make it unlikely they would respond to "pre-arrest" educational programs.

Given the relative futility of arrest and our belief that drunk drivers are impervious to appeals, what is left? Judicious curtailment or manipulation of alcohol sales will have to be considered, although this will undoubtedly raise howls of anguish from predictable sources and evoke pained silence from others. The protests will come from those who profit commercially from the production of alcoholic beverages - and their advertizing beneficiaries. The silence will come from government officials and legislators fearful of tax losses, irate voters, or both.

A reduction of alcohol consumption may be attempted in three ways: banning all advertizing, manipulating the hours during which alcoholic beverages can be sold, and increasing taxation.

The least painful approach for the general public would be a complete and total ban of all alcohol advertizing regardless of media or type of beverage. Given the appalling consequences of alcoholism and drunken driving it would seem that banning advertizing would be a small price to pay for an overall reduction of alcohol consumption. Schmidt [22] has posited that only through a reduction in total alcohol consumption can society anticipate any real drop in alcoholism rates. This reasoning can obviously be extended to the drunk driving syndrome. Unfortunately, there is no certainty that a total ban on alcohol advertizing will reduce consumption, but one suspects that it will. Comparisons with elimination of cigarette advertizing from U.S. television are not valid. When that ban took effect, other forms of advertizing ballooned.

Manipulating the hours when alcoholic beverages may be sold may well prove most helpful in controlling drunken driving and its related mishaps. Since these episodes are essentially night-time phenomena, experimentation with halting package sales at 3:00 p.m. or earlier and all liquor sales at 10:00 or 11:00 p.m. would be in order. It could be argued that one could still buy as much liquor as possible early in the day. True enough, but such purchases require planning and prudence, attributes that are obviously not common in drunk driving populations - and particularly absent during the hours prior to their arrests.

Increased taxation of alcoholic beverages is a proven method of reducing sales and hence consumption. However, it penalizes all drinkers indiscriminately and probably should be considered as a last resort, if at all.

\section{Acknowledgement}

This work was supported by NIAAA Grant No. AA00495-02. 


\section{References}

1 L. Goldberg, Drunken drivers in Sweden, Proc. 2nd Int. Conf. on Alcohol and Road Traffic, Addiction Research Foundation, Toronto, 1955.

2 W. Schmidt and R. Smart, Alcoholics, drinking and traffic accidents, Quart. J. Studies Alc., 20 (1959) 631.

3 M. Selzer, C. Payne, W. Kelly and J. Gifford, Alcoholism, Mental illness and the drunk driver, Amer. J. Psychiat., 120 (1963) 311.

4 N. Kaestner, V. Howard and E. Warmoth, Oregon Study of Drinking Drivers, Oregon Department of Transportation, 1969.

5 R. Yoder and R. Moore, Characteristics of convicted drunken drivers, Quart. J. Studies Alc., 34 (1973) 927.

6 M. Selzer and A. Vinokur, Driving and psychosocial characteristics of drunk drivers, 19th Annu. Conf. Amer. Ass. for Automotive Medicine, San Diego, U.S.A., 1975, Amer. Ass. for Auto Medicine, Lake Bluff, Ill., pp. 244 - 252.

7 M. Selzer, A. Vinokur and T. Wilson, A psychosocial comparison of drunk drivers and alcoholics, J. Studies Alc., July (1977) in press.

8 D. Crowne and D. Marlowe, The Approval Motive, J. Wiley, New York, 1964.

9 M. Selzer, The Michigan Alcoholism Screening Test (MAST): the quest for a new diagnostic instrument, Amer. J. Psychiat., 127 (1971) 1653.

10 M. Selzer, A. Vinokur and L. von Rooijen, A self-administered Short Michigan Alcoholism Screening Test (SMAST), J. Studies Alc., 36 (1975) 117.

11 D. Cahalan, I. Cisin, A. Kusch and C. Newcomb, Behavior and attitudes related to drinking in a medium-sized urban community in New England, Rep. 2, Social Res. Project, George Washington University, Washington, D.C., U.S.A., 1965.

12 J. Kulik, W. Revelle and C. Kulik, Scale Construction by Hierarchical Cluster Analysis, University of Michigan Center for Research on Learning and Teaching, Ann Arbor, 1972.

13 M. Rosenberg, Society and the Adolescent Self-Image, Princeton University Press, Princeton, 1965.

14 H. Eysenck, A short questionnaire for the measurement of two dimensions of personality, J. Applied Psychol., 42 (1958) 14.

15 E. Megargee, The California Psychological Inventory Handbook, Jossey-Bass, San Francisco, 1972.

16 A. Buss and A. Durkee, An inventory for assessing different kinds of hostility, J. Consult. Clin. Psychol. 21 (1957) 343.

17 W. Zung, A self-rating depression scale, Arch. Gen. Psychiat., 12 (1965) 63.

18 M. Selzer, Alcoholics and social drinkers: characteristics and differentiation; in Alcohol, Drugs and Traffic Safety, Addiction Research Foundation, Toronto, 1975, pp. $13-20$.

19 A. Wolfe, 1973 U.S. National Breath-Testings Survey, Highway Safety Research Institute, University of Michigan, Ann Arbor, 1974.

20 H. Ross, Law, science and accidents: the British Road Safety Act of 1967, J. Legal Studies, 11 (1973) 1.

$21 \mathrm{H}$. Ross, The Scandinavian myth : effectiveness of drinking-and-driving legislation in Sweden and Norway, J. Legal Studies, 4 (1975) 285.

22 W. Schmidt, Public health perspectives on alcohol problems with special reference to Canada, Proc 11th Annu. Conf. of the Canadian Foundation on Alcohol and Drug Dependencies, Toronto, Addiction Research Foundation, 1976. 